\title{
The mean platelet volume and plateletcrit as predictors of short-term outcome of acute ischemic stroke
}

\author{
Al-Amir Bassiouny Mohamed ${ }^{1 *}$ D, Hassan Mohamed Elnady ${ }^{1}$, Hazem Kamal Alhewaig ${ }^{1}$, \\ Hesham Moslem Hefny ${ }^{2}$ and Ashraf Khodery ${ }^{2}$
}

\begin{abstract}
Background: Activation of the platelet plays an important role in the process of atherosclerosis. Mean platelet volume (MPV) is significantly associated with the poor outcome of acute ischemic stroke while the results of studies about the relationship between plateletcrit $(P C T)$ and stroke outcome were inconsistent. The aim of this work is to determine whether an association exists between MPV and plateletcrit (PCT) and outcome of acute ischemic stroke.

Methods: We examined 157 patients with ischemic stroke, admitted to the Sohag University Hospital. The diagnosis of stroke was performed clinically according to The World Health Organization and confirmed by brain CT and MRI when needed. Platelet indices including MPV and PCT were assessed immediately (within $2 \mathrm{~h}$ ) after admission. After 3 months, the functional outcome was assessed using the modified Rankin Scale (mRS) with assessment of the relationship between platelet indices and stroke outcome.

Results: About $50 \%$ of the participants have favorable outcome. MPV was significantly higher in the unfavorable group $(10.4 \pm 2.3 \mathrm{fL})$ than in the favorable one $(8.7 \pm 1.3 \mathrm{fL})(P<0.001)$. MPV was an independent predictor of poor short-term outcome of acute stroke after controlling for confounders like diabetes mellitus. The mean PCT was significantly higher in the unfavorable group $(0.28 \pm 0.1 \%)$ than in the favorable one $(0.25 \pm 0.1 \%)(P=0.04)$ but not considered as an independent predictor of poor short-term outcome of acute stroke.

Conclusions: MPV and PCT were significantly correlated with poor functional outcome, only MPV was an independent predictor of poor short-term outcome of acute stroke after controlling for confounders like DM, and these platelet indices can be used as a prognostic tool.
\end{abstract}

Keywords: Mean platelet volume, Plateletcrit, Outcome, Stroke

\section{Introduction}

Under some pathological conditions like diabetes mellitus, obesity, metabolic syndrome, acute myocardial infarction (AMI), and stroke, the platelets may be larger in size and more reactive and this phenomenon seems to play an important role in several vascular diseases. Mean platelet volume (MPV) could be obtained from a simple and routine blood count and has a prognostic significance in stroke and AMI [1].

\footnotetext{
* Correspondence: airmohamed36@yahoo.com

${ }^{1}$ Department of Neurology and Psychological Medicine, Faculty of Medicine, Sohag University Hospital, Sohag, Egypt

Full list of author information is available at the end of the article
}

Platelet activation plays a key part in the process of atherosclerosis and then its potentially major adverse clinical outcomes, such as ischemic stroke and myocardial infarction (MI) [2-4]. It is well documented that there is a direct relationship between the platelet physiology and ischemic stroke by a number of observations, including the appearance of platelet thrombi on atheroma, and certain antiplatelet agents (e.g., aspirin) significantly reduce the incidence of ischemic stroke after initial transient ischemic attacks [5-8], and so measuring the platelet function by platelet indices (MPV and PCT) is useful in various clinical situations.

Many existing studies investigate the relationships between MPV and prognosis of coronary diseases [8-10], 
but studies between platelet indices and cerebrovascular accidents are lacking. Some studies found that increased MPV is associated with different stroke subtypes $[8,11$, 12] while another study reported that MPV has been shown to be predictive of stroke recurrence [13].

PCT (also called platelet mass) is the volume occupied by platelets in the blood as a percentage and calculated according to the formula ( $\mathrm{PCT}=$ platelet count $\times \mathrm{MPV} /$ $10,000)$. The number of platelets in the blood is maintained in an equilibrium state by regeneration and elimination [14-16].

Under physiologic conditions, the rate of platelet production is continuously regulated so that the circulating platelet mass (platelet count X MPV) is kept constant, and both MPV and platelet count are inversely associated $[17,18]$.

Platelet mass can be derived from data obtained from the routine full blood count and was accepted as an indicator of circulating platelets in a unit volume of blood $[19,20]$.

The available data regarding the relationships between antiplatelet drugs and large platelets are lacking. Particularly, aspirin does not seem to significantly affect platelet volume, either in vitro or in vivo [21]. Conversely, large platelets may have an increased reactivity even in patients with stable coronary artery disease undergoing dual antiplatelet therapy with aspirin and clopidogrel [22].

The goal of this study is to determine out whether an association exists between MPV and PCT and outcome of acute ischemic stroke.

\section{Patients and methods}

This prospective study includes 100 and 57 consecutive patients (36.9\% males and $63.1 \%$ females) with acute ischemic stroke, admitted from August 2013 to October 2014 to the Neurology Department, Sohag University Hospital.

We obtained an informed consent and written when possible from the patients or relative. The study was approved by the local ethical committee of Faculty of Medicine, Sohag University in April 2013.

These patients were attended for first-ever acute ischemic stroke, which is defined as focal neurological signs or symptoms thought to be of vascular origin that persisted for $>24 \mathrm{~h}$ [23] confirmed by brain computed tomography (CT) and/or MRI. Those with clinical data corresponding to stroke with normal brain CT scan result were also considered as ischemic stroke, but another CT scan was done after 2 days to measure the maximum lesion diameter. The cerebral lesions whose maximum diameter was $\geq 4 \mathrm{~cm}$ were considered large infarction [12].

We exclude patients with transient symptoms of cerebrovascular diseases, peripheral vascular disease, acute infection, positive $\mathrm{C}$-reactive protein or inflammatory conditions, prior stroke, acute myocardial infarction, malignancies, and intracranial hemorrhage. Also, patients who administered medications including anti-lipids, angiotensin-converting enzyme inhibitors, and anticoagulants were also excluded.

No patient underwent IV or IA thrombolysis, during the study period, but the participants received the usual antiplatelet treatment.

Full medical and neurological evaluation was done for all patients, including demographics; vascular risk profile; medical history, especially the former history of ischemic heart disease or stroke; biochemical parameters; medications that may affect platelet count; echocardiographic data; and neuroimaging studies. Canadian stroke scale (CSS) was done to determine stroke severity with a score of 6.5 on CSS as a cut point to differentiate a more and less severe stroke, and lower scores indicate greater stroke severity $[24,25]$.

Glasgow coma scale was used to assess conscious level of the patient and was graded as mildly disturbed (GCS $=13$ $15)$, moderately disturbed $(\mathrm{GCS}=9-12)$, and severely disturbed $(\mathrm{GCS} \leq 8)[26]$.

For the assessment of blood pressure, high blood pressure was defined as the use of anti-hypertensive drugs or persistently elevated blood pressure $(>140 / 90 \mathrm{mmHg})$ on admission.

Diabetes mellitus was defined as the use of hypoglycemic agents or a fasting plasma glucose of > $126 \mathrm{mg} / \mathrm{dl}$ (after no caloric intake for at least $8 \mathrm{~h}$ ) or casual plasma glucose $>200 \mathrm{mg} / \mathrm{dl}$ [27].

All patients underwent blood sampling immediately after admission to the Neurology Department and before administration of medication or intravenous fluid. A complete blood count was performed, and the platelet parameters obtained. The samples were collected in EDTA tubes and transported to the laboratory. Platelet measurements were performed within $2 \mathrm{~h}$ to ensure minimal platelet swelling [28, 29] by a Cell Dyn 3700 hematology analyzer that provided platelet count and MPV (in $\mathrm{fL})$. PCT (expressed in percentage) is determined by multiplying the platelet number in thousands by mean platelet volume in femtoliters and dividing that product by 10,000 . PCT was determined by using the same equation as the Cell Dyn 3700 hematology analyzer: $\mathrm{PCT}=(\mathrm{PLT} \times \mathrm{MPV}) / 10,000[10]$.

Typically, the average mean platelet volume is $7.2-$ $11.7 \mathrm{fL}$ in healthy subjects while the normal range for PCT is $0.22-0.24 \%$ [30, 31].

Other routine laboratory investigations were done like liver function tests, renal function tests, and blood sugar test. Lipogram was done; cholesterol level was considered normal when total cholesterol is less than $200 \mathrm{mg} / \mathrm{dL}$; LDL ("bad" cholesterol) level is less than $100 \mathrm{mg} / \mathrm{dL}$, while HDL ("good" cholesterol) level is $60 \mathrm{mg} / \mathrm{dL}$ or higher; and normal triglycerides is less than $150 \mathrm{mg} / \mathrm{dL}$ [32].

The outcome of ischemic stroke was assessed after 3 months of the insult by modified Rankin Scale (mRS) 
that scores patients on a scale from 0 to 6 , with 0 being asymptomatic and 6 being dead. Scores of $0-2$ are considered "favorable" stroke outcomes while scores of 3 or greater indicate "unfavorable" outcomes [33, 34].

\section{Statistical analyses}

The data were analyzed by Statistical Package for the Social Sciences (SPSS 20.0, IBM Corp., Armonk, NY, USA).

The groups with the different ischemic stroke outcome were compared using the Student's $t$ test for the continuous variables and the chi-square test for the categorical variables. Predictors exhibiting a statistically significant relation with poor outcome $(\mathrm{mRS} \geq 3)$ were taken for multivariate logistic regression analysis to investigate their independence as predictors. The adjusted odds ratio (OR) and $95 \%$ confidence intervals $(\mathrm{CI})$ were calculated. Statistical significance was determined at $P \leq 0.05$.

\section{Results}

A total of 157 patients with first-ever ischemic stroke with a mean age of $56.7 \pm 16.2$ years, and $36.9 \%$ males and $63.1 \%$ females were included to this study (Table 1).

The favorable outcome was $51.6 \%$, whereas the unfavorable one was $48.4 \%$. Table 1 and Table 2 summarize the main characteristics of the patients in both groups. Age was significantly correlated with patients of the unfavorable group $(P$ value $<0.001)$. Patients with favorable outcome were less likely to have a history of hypertension and cardiac diseases. Mean platelet volume and PCT were significantly higher in patients with unfavorable outcome with $P$ value $<0.001$ and $P$ value $=0.041$ respectively. Table 3 shows multivariate logistic regression analysis and odds ratios for each of the factors. The significant factors in the model were age $(P$ value $=$ $0.001)$, MPV $(P$ value $<0.001)$, DM $(P$ value $=0.046)$, and triglycerides $(P$ value $=0.008)$ which were considered as independent predictors for stroke outcome after controlling for confounders like age, DM, and triglycerides.

\section{Discussion}

Increased platelet volume may interpret the net patho-physiological effects of a number of cerebrovascular diseases (CVD) risk factors, such as smoking and elevated cholesterol, therefore presenting a broad marker of CVD risk. Several studies reported that high MPV levels is associated with overall vascular mortality in the general population [35-38]. In contrast, some studies did not reveal any relationship between platelet volume and function with the outcome of ischemic stroke which may be explained by time-dependent platelet swelling in vitro and the influence of MPV by various comorbidities and concomitant drug therapies like antiplatelet and perindopril $[9,39,40]$. There is a current growing
Table 1 Baseline characteristics of patients

\begin{tabular}{|c|c|c|}
\hline & Number & Percent \\
\hline Age (mean $\pm S D)$ & $56.72 \pm 16.218$ & \\
\hline \multicolumn{3}{|l|}{ Sex } \\
\hline Male & 58 & $(36.9)$ \\
\hline Female & 99 & $(63.1)$ \\
\hline \multicolumn{3}{|l|}{ Smoking } \\
\hline Nonsmoker & 129 & $(82.2)$ \\
\hline Smoker & 28 & $(17.8)$ \\
\hline Hypertensive & 67 & $(42.7)$ \\
\hline $\mathrm{SBP}($ mean $\pm \mathrm{SD})$ & $144.8 \pm 27.0$ & \\
\hline $\mathrm{DBP}($ mean $\pm \mathrm{SD})$ & $94.7 \pm 22.43$ & \\
\hline DM & 50 & $(31.8)$ \\
\hline Blood glucose level (mean \pm SD) & $129.6 \pm 63.2$ & \\
\hline Cardiac & 33 & $(21.0)$ \\
\hline \multicolumn{3}{|l|}{ Platelet indices } \\
\hline MPV (mean \pm SD) & $10.3 \pm 2.6$ & \\
\hline $\mathrm{PCT}($ mean $\pm \mathrm{SD})$ & $0.26 \pm 0.11$ & \\
\hline \multicolumn{3}{|l|}{ Lipogram } \\
\hline Total cholesterol (mean \pm SD) & $183.4 \pm 46.3$ & \\
\hline Triglycerides (mean $\pm \mathrm{SD}$ ) & $131.1 \pm 66.04$ & \\
\hline LDL (mean $\pm S D)$ & $114.6 \pm 45.05$ & \\
\hline $\mathrm{HDL}($ mean $\pm \mathrm{SD})$ & $39.1 \pm 10.4$ & \\
\hline \multicolumn{3}{|l|}{ Lesion size (CT and/or MRI) } \\
\hline Less than $4 \mathrm{~cm}$ & 134 & $(85.4)$ \\
\hline$\geq 4 \mathrm{~cm}$ & 23 & $(14.6)$ \\
\hline \multicolumn{3}{|l|}{ Conscious level measured by GCS) } \\
\hline \multicolumn{3}{|l|}{ Canadian stroke } \\
\hline Mild to moderate stroke & 86 & 54.8 \\
\hline Severe stroke & 71 & 45.2 \\
\hline Mildly disturbed (13-15) & 107 & 68.2 \\
\hline Moderately disturbed (9-12) & 48 & 30.6 \\
\hline Severely disturbed $(\leq 8)$ & 2 & 1.3 \\
\hline \multicolumn{3}{|l|}{ Outcome (measured by mRS) } \\
\hline Favorable outcome & 81 & 51.6 \\
\hline Unfavorable outcome $>3$ & 76 & 48.4 \\
\hline
\end{tabular}

$S B P$ systolic blood pressure, $D B P$ diastolic blood pressure, DM diabetes mellitus, MPV mean platelet volume, $P C T$ plateletcrit, $L D L$ low-density lipoprotein, $H D L$ high-density lipoprotein, $C T$ computerized tomography, MRI magnetic resonance imaging, GCS Glasgow coma scale, $m R S$ modified Rankin scale

evidence that platelet indices including MPV and PCT are significantly correlated with vascular risk factors and can predict prognosis of acute ischemic stroke [2-4, 41].

The result of this work demonstrated that increased MPV is associated with poor functional outcome of stroke and highlighted the importance of MPV as an independent predictor for stroke outcome after controlling for 
Table 2 Characteristic of patients in both favorable and unfavorable groups

\begin{tabular}{|c|c|c|c|}
\hline & $\begin{array}{l}\text { Favorable outcome } \\
\text { MRS } \leq 2(N=81)\end{array}$ & $\begin{array}{l}\text { Unfavorable outcome } \\
\text { MRS }>3(N=76)\end{array}$ & $P$ value \\
\hline Age & $51 \pm 17.8$ & $62.7 \pm 11.6$ & $<0.001$ \\
\hline Sex & & & 0.524 \\
\hline Male & $28(34.6 \%)$ & $30(39.5 \%)$ & \\
\hline Female & $53(65.4 \%)$ & $46(60.5 \%)$ & \\
\hline Smoking & $12(14.8 \%)$ & $16(21.1 \%)$ & 0.308 \\
\hline Cardiac disease & $10(12.3 \%)$ & $23(30.3 \%)$ & 0.006 \\
\hline Hypertensive & $22(27.2 \%)$ & $45(59.2 \%)$ & $<0.001$ \\
\hline Diabetic & $12(14.8 \%)$ & $26(34.2 \%)$ & 0.005 \\
\hline GCS & $14.3 \pm 1.3$ & $12.62 \pm 2.3$ & $<0.001$ \\
\hline \multicolumn{4}{|l|}{ Platelet measurements } \\
\hline MPV & $8.7 \pm 1.3$ & $10.4 \pm 2.3$ & $<0.001$ \\
\hline Plateletcrit (PCT) & $0.25 \pm 0.10$ & $0.28 \pm 0.12$ & 0.041 \\
\hline Canadian stroke scale & $8.1 \pm 2.3$ & $4.6 \pm 3.2$ & $<0.001$ \\
\hline
\end{tabular}

mRS modified Rankin scale, GCS Glasgow coma scale

confounders like DM which is confirmed by previous studies [11].

Previous studies reported that higher MPV was associated with the larger infarct size and higher risk of post-stroke mortality [12, 42].

On the contrary, two studies $[39,43]$ did not find any significant relation between MPV and stroke outcome and the causes for these inconsistent findings could be explained by small numbers of patients and the use of different methodological measures of platelet indices and different outcome scales in these studies [28].

The studies conducted to detect the relationship between PCT and stroke outcome are lacking, and the results were conflicting; one earlier study found no difference in platelet mass in stroke patients compared to control [9] while the other found a decrease in platelet count, MPV, and plateletcrit in patients with lacunar infarction [10].

Table 3 Predictors of stroke outcome by using multivariate logistic regression analysis for determining the role of MPV and PCT in predicting stroke outcome

\begin{tabular}{|c|c|c|c|c|c|c|}
\hline \multirow[t]{2}{*}{ Characteristics } & \multirow{2}{*}{$\begin{array}{l}\text { Regression } \\
\text { coefficients } \beta\end{array}$} & \multirow[t]{2}{*}{ SE } & \multirow{2}{*}{$\begin{array}{l}\text { Odds } \\
\text { ratio }\end{array}$} & \multicolumn{2}{|c|}{ 95\% C.I. } & \multirow[t]{2}{*}{$P$ value } \\
\hline & & & & Lower & Upper & \\
\hline Age & 0.060 & 0.017 & 1.062 & 1.027 & 1.099 & 0.001 \\
\hline DM & 1.036 & 0.520 & 2.817 & 1.016 & 7.809 & 0.046 \\
\hline MPV & 0.432 & 0.105 & 1.540 & 1.253 & 1.893 & $<0.001$ \\
\hline PCT & 0.430 & 2.359 & 1.537 & 0.015 & 156.369 & 0.855 \\
\hline Cholesterol & 0.007 & 0.006 & 1.007 & 0.996 & 1.019 & 0.207 \\
\hline Triglycerides & -0.010 & 0.004 & 0.990 & 0.982 & .997 & 0.008 \\
\hline Constant & -8.359 & 1.973 & 0.000 & & 1.099 & \\
\hline
\end{tabular}

MPV mean platelet volume, PCT plateletcrit, SE standard error
Like previous studies, the present work confirms that increased MPV and subsequent higher platelet mass (plateletcrit) are significantly correlated with short-term outcome of ischemic stroke [11, 28, 41] but not considered as independent predictor, and further studies are warranted to explain this correlation.

The mechanisms by which elevated MPV might play a role in the development or progression of cardiovascular diseases are not completely understood, but there are some possible explanations. First, platelet reactivity is increased with ischemic stroke as evidenced by the increased levels of soluble platelet $\mathrm{P}$-selectin and increased levels of thromboxane A2 which are considered as atherogenic factors [44, 45]. Second, cytokines such as interleukin-3 or interleukin-6 which plays an important role in the pathophysiology of ischemic stroke influence megakaryocyte ploidy which in turn affect the platelet size and can lead to the production of more reactive, larger platelets [28] and so the proinflammatory condition before the ischemic stroke may lead to a higher MPV which in turn lead to prothrombotic condition. Finally, large platelets may be a consequence of secretion and metabolism of biologically active substances during aging, diabetes, high blood pressure, and obesity and consequently cause increased risk of ischemic stroke [41, 46, 47].

\section{Limitations}

This study has some limitations. One is changeability of platelet size because of time-dependent platelet swelling in vitro using EDTA as an anticoagulant. Second, serial MPV measurements were not done during different stages of stroke and so variability of platelet size during stroke evolutions could not be estimated. 


\section{Conclusion}

The present study exhibits an association between MPV and PCT and acute ischemic stroke functional outcome. These findings raise the potential importance of MPV and PCT as easily obtained during routine hematologic analysis, as a valuable prognostic tool for outcome of cerebrovascular stroke. Further research is required to accurately determine the role of platelet volume in stroke pathology, outcome, and, most importantly, in individuals at risk for stroke.

\section{Abbreviation}

CSS: Canadian stroke scale; CVD: Cerebrovascular diseases; MI: Myocardial infarction; MPV: Mean platelet volume; mRS: Modified Rankin Scale; PCT: Plateletcrit

\section{Acknowledgements}

None

\section{Funding}

None

\section{Availability of data and materials}

The data set of this work is available and uploaded with this article.

\section{Authors' contributions}

ABM chose the search idea; participated in the development of the research plan, analysis and discussion of the results, and research review; and conducted and applied the research. HME participated in the development of the research plan, the analysis and discussion of the results, the writing of the research, and the research review. HKA participated in the analysis and discussion of the results, in writing the research, and in the research review. $\mathrm{HMH}$ participated in the analysis and discussion of the results, in writing the research, and in the research review. AK participated in the analysis and discussion of the results and in the research review. All authors read and approved the final manuscript.

\section{Ethics approval and consent to participate}

The study was approved by the local ethical committee of Sohag Faculty of Medicine, Sohag University, April 2013.

Informed written (when available) consent was obtained from all patients for the participation and publication of this study.

\section{Consent for publication}

This manuscript does not contain any personal data.

\section{Competing interests}

The authors declare that they have no competing interests.

\section{Publisher's Note}

Springer Nature remains neutral with regard to jurisdictional claims in published maps and institutional affiliations.

\section{Author details}

${ }^{1}$ Department of Neurology and Psychological Medicine, Faculty of Medicine, Sohag University Hospital, Sohag, Egypt. ${ }^{2}$ Department of Clinical Pathology, Faculty of Medicine, Sohag University Hospital, Sohag, Egypt.

Received: 4 October 2017 Accepted: 23 October 2018

Published online: 08 January 2019

\section{References}

1. Vizioli L, Muscari S, Muscari A. The relationship of mean platelet volume with the risk and prognosis of cardiovascular diseases. Int J Clin Pract. 2009; 63(10):1509-15.

2. Boos CJ, Lip GY. Platelet activation and cardiovascular outcomes in acute coronary syndromes. J Thromb Haemost. 2006;4(12):2542-3 Epub 2006/10/10
3. Tsiara S, Elisaf M, Jagroop IA, Mikhailidis DP. Platelets as predictors of vascular risk: is there a practical index of platelet activity? Clin Appl Thromb Hemost. 2003;9(3):177-90 Epub 2003/09/26.

4. Jesty J, Yin W, Perrotta P, Bluestein D. Platelet activation in a circulating flow loop: combined effects of shear stress and exposure time. Platelets. 2003; 14(3):143-9 Epub 2003/07/10.

5. del Zoppo GJ. The role of platelets in ischemic stroke. Neurology. 1998;51(3 Suppl 3):S9-14 Epub 1998/09/23.

6. Sharp DS, Benowitz NL, Bath PM, Martin JF, Beswick AD, Elwood PC Cigarette smoking sensitizes and desensitizes impedance-measured ADPinduced platelet aggregation in whole blood. Thromb Haemost. 1995;74(2): 730-5 Epub 1995/08/01.

7. Bath PM, Butterworth RJ. Platelet size: measurement, physiology and vascular disease. Blood Coagul Fibrinolysis. 1996;7(2):157-61 Epub 1996/03/01.

8. Butterworth RJ, Bath PM. The relationship between mean platelet volume, stroke subtype and clinical outcome. Platelets. 1998;9(6):359-64 Epub 2006/ $06 / 24$.

9. O'Malley T, Langhorne P, Elton RA, Stewart C. Platelet size in stroke patients. Stroke. 1995;26(6):995-9.

10. Tohgi H, Suzuki H, Tamura K, Kimura B. Platelet volume, aggregation, and adenosine triphosphate release in cerebral thrombosis. Stroke. 1991;22(1): 17-21 Epub 1991/01/01

11. Mayda-Domac F, Misirli H, Yilmaz M. Prognostic role of mean platelet volume and platelet count in ischemic and hemorrhagic stroke. J Stroke Cerebrovasc Dis. 2010;19(1):66-72 Epub 2010/02/04.

12. Muscari A, Puddu GM, Cenni A, Silvestri MG, Giuzio R, Rosati M, et al. Mean platelet volume (MPV) increase during acute non-lacunar ischemic strokes. Thromb Res. 2009;123(4):587-91 Epub 2008/05/13.

13. Bath P, Algert C, Chapman N, Neal B. Association of mean platelet volume with risk of stroke among 3134 individuals with history of cerebrovascular disease. Stroke. 2004;35(3):622-6 Epub 2004/02/21.

14. Chandrashekar V. Plateletcrit as a screening tool for detection of platelet quantitative disorders. J Hematol. 2013;2(1):22-6.

15. Budak YU, Polat M, Huysal K. The use of platelet indices, plateletcrit, mean platelet volume and platelet distribution width in emergency non-traumatic abdominal surgery: a systematic review. Biochemia Medica. 2016;26(2):178-93.

16. Giacomini A, Legovini P, Gessoni G, Antico F, Valverde S, Salvadego M, et al. Platelet count and parameters determined by the Bayer ADVIATM 120 in reference subjects and patients. Int J Lab Hematol. 2001;23(3):181-6.

17. Jakubowski JA, Thompson CB, Vaillancourt $R$, Valeri CR, Deykin D. Arachidonic acid metabolism by platelets of differing size. $\mathrm{Br} J$ Haematol. 1983;53(3):503-11.

18. Arévalo-Lorido JC, Carretero-Gómez J, Álvarez-Oliva A, Gutiérrez-Montaño C, Fernández-Recio JM, Najarro-Díez F. Mean platelet volume in acute phase of ischemic stroke, as predictor of mortality and functional outcome after 1 year. J Stroke Cerebrovasc Dis. 2013;22(4):297-303.

19. Bain BJ, Lewis SM, Bates I. Basic haematological techniques. Dacie Lewis Pract Haematol. 2006;4:19-46.

20. Bowles KM, Warner BA, Baglin TP. Platelet mass has prognostic value in patients with myelodysplastic syndromes. Br J Haematol. 2006;135(2):198200.

21. Erhart S, Beer JH, Reinhart WH. Influence of aspirin on platelet count and volume in humans. Acta Haematol. 1999:101(3):140-4.

22. Guthikonda S, Alviar CL, Vaduganathan M, Arikan M, Tellez A, DeLao T, et al. Role of reticulated platelets and platelet size heterogeneity on platelet activity after dual antiplatelet therapy with aspirin and clopidogrel in patients with stable coronary artery disease. J Am Coll Cardiol. 2008;52(9): 743-9.

23. WHO MONICA Project Principal Investigators. The World Health Organization MONICA Project (monitoring trends and determinants in cardiovascular disease): a major international collaboration. J Clin Epidemiol. 1988:41(2):105-14.

24. Cote R, Hachinski V, Shurvell B, Norris J, Wolfson C. The Canadian Neurological Scale: a preliminary study in acute stroke. Stroke. 1986;17(4):731-7.

25. Cote R, Battista R, Wolfson C, Boucher J, Adam J, Hachinski V. The Canadian neurological scale validation and reliability assessment. Neurology. 1989; 39(5):638

26. Teasdale $G$, Jennett B. Assessment of coma and impaired consciousness. A practical scale. Lancet. 1974;2(7872):81-4.

27. Association AD. Clinical practice recommendations 2005. Diabetes Care 2005;28:S1. 
28. Greisenegger S, Endler G, Hsieh K, Tentschert S, Mannhalter C, Lalouschek W. Is elevated mean platelet volume associated with a worse outcome in patients with acute ischemic cerebrovascular events? Stroke. 2004;35(7): 1688-91.

29. Endler $G$, Klimesch A, Sunder-Plassmann H, Schillinger M, Exner M, Mannhalter $C$, et al. Mean platelet volume is an independent risk factor for myocardial infarction but not for coronary artery disease. Br J Haematol. 2002;117(2):399-404 Epub 2002/04/26.

30. Demirin H, Ozhan H, Ucgun T, Celer A, Bulur S, Cil H, et al. Normal range of mean platelet volume in healthy subjects: insight from a large epidemiologic study. Thromb Res. 2011;128(4):358-60.

31. Wiwanitkit V. Plateletcrit, mean platelet volume, platelet distribution width: its expected values and correlation with parallel red blood cell parameters. Clin Appl Thromb Hemost. 2004;10(2):175-8.

32. Expert Panel on Detection E. Executive summary of the Third Report of the National Cholesterol Education Program (NCEP) expert panel on detection, evaluation, and treatment of high blood cholesterol in adults (Adult Treatment Panel III). JAMA. 2001;285(19):2486.

33. Abubakar SA, Okubadejo NU, Ojo OO, Oladipo O, Ojini FI, Danesi MA. Relationship between admission serum C-reactive protein and short term outcome following acute ischaemic stroke at a tertiary health institution in Nigeria. Niger J Clin Pract. 2013;16(3):320.

34. Uyttenboogaart M, Stewart RE, Vroomen PC, De Keyser J, Luijckx GJ. Optimizing cutoff scores for the Barthel index and the modified Rankin scale for defining outcome in acute stroke trials. Stroke. 2005;36(9):1984-7.

35. Boos CJ, Balakrishnan B, Lip GY. The effects of coronary artery disease severity on time-dependent changes in platelet activation indices in stored whole blood. J Thromb Thrombolysis. 2008;25(2):135-40 Epub 2007/06/19.

36. Klovaite J, Benn M, Yazdanyar S, Nordestgaard BG. High platelet volume and increased risk of myocardial infarction: 39,531 participants from the general population. J Thromb Haemost. 2011;9(1):49-56 Epub 2010/10/15.

37. Chu SG, Becker RC, Berger PB, Bhatt DL, Eikelboom JW, Konkle B, et al. Mean platelet volume as a predictor of cardiovascular risk: a systematic review and meta-analysis. J Thromb Haemost. 2010;8(1):148-56 Epub 2009/08/21.

38. Slavka G, Perkmann T, Haslacher H, Greisenegger S, Marsik C, Wagner OF, et al. Mean platelet volume may represent a predictive parameter for overall vascular mortality and ischemic heart disease. Arterioscler Thromb Vasc Biol. 2011;31(5):1215-8 Epub 2011/02/19

39. Ntaios G, Gurer O, Faouzi M, Aubert C, Michel P. Mean platelet volume in the early phase of acute ischemic stroke is not associated with severity or functional outcome. Cerebrovasc Dis. 2010;29(5):484-9 Epub 2010/03/20.

40. McCabe DJ, Harrison P, Sidhu PS, Brown MM, Machin SJ. Circulating reticulated platelets in the early and late phases after ischaemic stroke and transient ischaemic attack. Br J Haematol. 2004;126(6):861-9 Epub 2004/09/09.

41. Boos CJ, Lip GY. Assessment of mean platelet volume in coronary artery disease - what does it mean? Thromb Res. 2007;120(1):11-3 Epub 2006/10/19.

42. Pikija S, Cvetko D, Hajduk M, Trkulja V. Higher mean platelet volume determined shortly after the symptom onset in acute ischemic stroke patients is associated with a larger infarct volume on $C T$ brain scans and with worse clinical outcome. Clin Neurol Neurosurg. 2009;111(7):568-73 Epub 2009/05/19.

43. D'Erasmo E, Aliberti G, Celi FS, Romagnoli E, Vecci E, Mazzuoli GF. Platelet count, mean platelet volume and their relation to prognosis in cerebral infarction. J Intern Med. 1990;227(1):11-4.

44. Nadar SK, Lip GY, Blann AD. Platelet morphology, soluble P selectin and platelet P-selectin in acute ischaemic stroke. The West Birmingham Stroke Project. Thromb Haemost. 2004;92(6):1342-8 Epub 2004/12/08.

45. Borissoff $\mathrm{J}$, Spronk HM, ten Cate $H$. The hemostatic system as a modulator of atherosclerosis. N Engl J Med. 2011;364(18):1746-60 Epub 2011/05/06

46. Papanas N, Symeonidis G, Maltezos E, Mavridis G, Karavageli E, Vosnakidis T, et al. Mean platelet volume in patients with type 2 diabetes mellitus. Platelets. 2004;15(8):475-8 Epub 2005/03/15.

47. Coban E, Ozdogan M, Yazicioglu G, Akcit F. The mean platelet volume in patients with obesity. Int J Clin Pract. 2005;59(8):981-2 Epub 2005/07/22.

\section{Submit your manuscript to a SpringerOpen ${ }^{\odot}$ journal and benefit from:}

- Convenient online submission

- Rigorous peer review

- Open access: articles freely available online

- High visibility within the field

- Retaining the copyright to your article

Submit your next manuscript at $\boldsymbol{\nabla}$ springeropen.com 